\title{
DENGUE OUTBREAK IN MATO GROSSO STATE, MIDWESTERN BRAZIL
}

Letícia Borges da Silva HEINEN(1), Nayara ZUCHI(1), Belgath Fernandes CARDOSO(1), Marcelo Adriano Mendes dos SANTOS(2), Mauricio Lacerda NOGUEIRA(3) \& Renata DEZENGRINI-SLHESSARENKO(1)

\begin{abstract}
SUMMARY
Dengue virus (DENV) is the most frequent arbovirus worldwide. In this study, we report a large outbreak in Mato Grosso State (MT). Serum samples from 604 patients with acute febrile illness for less than five days were inoculated in C6/36 cells, then infected cells were subjected to an indirect immunofluorescence test for DENV serotypes and yellow fever virus. Serum samples were submitted to a multiplex-semi-nested-RT-PCR for 11 flaviviruses. DENV-4 was isolated in 150/604 (24.8\%) and DENV-1 in 19/604 (3.1\%) specimens. By RT-PCR, 331 (54.8\%) samples tested positive for DENV; 321 had single infections $(\mathrm{DENV}-4 \mathrm{n}=305$; DENV-1 n = 15; DENV-3 $\mathrm{n}=1$ ), nine had co-infections of DENV-1/DENV-4, and one of DENV-2/DENV-4. DENV-4 was detected in $315 / 331$ (95.2\%) positive patients from 17 municipalities, and DENV-1 in 24/331 (7.2\%) patients from five cities in north-central MT and the city of Cuiaba. The incidence of infection was higher in patients aged 20-39 (142/331; 42.9\%). The NS5 partial nucleotide sequence of DENV-1 was most similar to that of genotype V, DENV-2 to Southeast Asian/American, DENV-3 to genotype III, and DENV-4 to genotype II strains, considered the most frequent strains in Brazil. This outbreak coincided with the introduction of DENV-4 in the state. Cuiaba was hyperendemic for the four DENV serotypes, highlighting the necessity for arbovirus surveillance in MT.
\end{abstract}

KEYWORDS: Arbovirus; DENV; Virological surveillance; Epidemiology; Molecular detection.

\section{INTRODUCTION}

Arboviruses are frequently associated with worldwide outbreaks, posing a significant risk to public health. The Flavivirus genus comprises several human pathogens associated with undifferentiated acute febrile illness, hemorrhagic fever, or encephalitis; these pathogens include dengue (DENV), yellow fever (YFV), Saint Louis encephalitis (SLEV), West Nile (WNV) and Rocio (ROCV) viruses ${ }^{18}$.

Flaviviruses are enveloped viruses, containing an icosahedral nucleocapsid and a single-stranded positive-sense genomic RNA of approximately $11 \mathrm{~kb}$. A single open reading frame encodes a polyprotein processed into three structural $(\mathrm{C}$, prM, and $\mathrm{E})$ and seven nonstructural (NS1, NS2A, NS2B, NS3, NS4A, NS4B, and NS5) proteins ${ }^{16,22}$.

DENV has become the most important arbovirus for public health, causing large urban outbreaks mainly in tropical and subtropical areas worldwide $^{43}$. There are at least four closely related, but antigenically distinct, DENV serotypes (DENV-1 to -4) and several intra-serotype genotypes with up to $6 \%$ divergence in the E/NS1 region ${ }^{19}$. Additionally, different lineages within a given genotype have been described ${ }^{10,44}$. Intra-serotype genotypes and lineages have been shown to vary in their virulence and, therefore, in their tendency to produce severe disease ${ }^{44}$. DENV is maintained in urban transmission cycles by the day-biting anthropophilic mosquitoes Aedes (Ae.) aegypti and Ae. albopictus ${ }^{40}$.

Clinical infection was previously classified as dengue fever (DF) and dengue hemorrhagic fever (DHF) grades I-IV; grades III and IV comprised the dengue shock syndrome (DSS) ${ }^{18}$. According to the criteria revised by the World Health Organization (WHO), the disease is currently classified as dengue with or without warning signs and severe dengue ${ }^{3,42}$. Lately, atypical forms of the disease, accompanied by myocarditis, hepatitis, meningoencephalitis, and/or acute kidney failure have also been reported ${ }^{12}$.

Only nine countries reported large dengue outbreaks before 1970 . However, since 1990, the global incidence of dengue has increased dramatically due to human travel, urban population expansion, and climate conditions propitiating Ae. aegypti proliferation ${ }^{1}$. Currently, dengue has reached global endemicity, with more than 100 countries affected in the Americas, Western Pacific and Southeast Asia ${ }^{43}$.

In Brazil, the first evidences of DENV circulation were observed in the state of Sao Paulo (SP) in 1916, and in the state of Rio de Janeiro (RJ) in $1923^{25,31}$. The lack of reports between 1924 and 1981 was attributed to the eradication of Ae. aegypti ${ }^{11}$. Reemergence of vector populations was followed by reports of DENV-1 and DENV-4 outbreaks during 1981-1982 in Boa Vista, in the state of Roraima (RR), in northern Brazil ${ }^{11}$.

(1) Universidade Federal de Mato Grosso, Faculdade de Medicina, Programa de Pós-Graduação em Ciências da Saúde, Cuiabá, Mato Grosso, Brasil.

(2) Secretaria Estadual de Saúde, Laboratório Central de Saúde Pública, Cuiabá, Mato Grosso, Brasil.

(3) Faculdade de Medicina de São José do Rio Preto, Laboratório de Pesquisa em Virologia, São José do Rio Preto, São Paulo, Brasil.

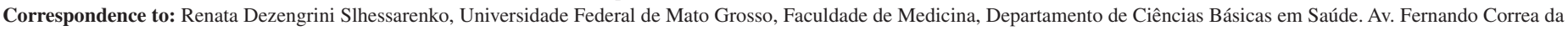
Costa 2367 CCBS-I sala 82, 78060-900 Cuiabá, Mato Grosso, Brasil; Tel: +55-65-9213-7333. E-mail: renatadezengrini@yahoo.com.br 


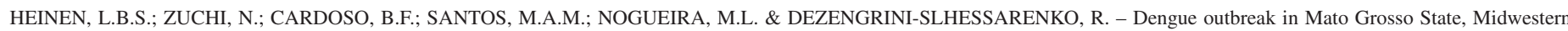
Brazil. Rev. Inst. Med. Trop. Sao Paulo. 57(6): 489-96, 2015.

Dengue reappeared in 1986, and cases of infection have, since then, been continuously reported in Brazil. Between 1986 and 1990, DENV-1 was responsible for outbreaks in RJ and other Brazilian States ${ }^{11}$. The first autochthonous case of DENV-2 infection was identified in RJ in $1990^{29}$. Both serotypes continued to circulate in subsequent years, resulting in the first DHF cases in Brazil ${ }^{11,39}$. DENV-3 dissemination occurred after its introduction in RJ in $2000^{28}$. DENV-4 genotype I was first identified in patients without travel history from Manaus, Amazonas (AM) in 2008. DENV-4 genotype II was introduced in Boa Vista, RR in 2010, disseminating to several states in the subsequent years ${ }^{13,36}$.

Nowadays, all four serotypes co-circulate in the Brazilian territory with varying frequencies among the different regions. Several events of clade replacements have occurred, and co-circulation of different intra-serotype genotypes and lineages has also been described in the country ${ }^{10}$. Introduction of new serotypes, genotypes or lineages within the same genotype, and the co-circulation of these viruses, contribute to the increased incidence, morbidity, and mortality of the disease ${ }^{14,35}$.

A higher incidence of dengue was evidenced mainly in northern, northeastern, and midwestern regions of Brazil after 1997, which is likely attributed to areas in which the socio-environmental conditions are favorable for Ae. aegypti proliferation ${ }^{37}$. Nowadays, dengue epidemics occur cyclically in the state of Mato Grosso (MT), midwestern Brazil, especially after 1995, coinciding with an intense demographic influx ${ }^{35}$. Data from the Brazilian Ministry of Health Information System for Notifiable Diseases (SINAN) indicate that at least 44,814 cases and 25 deaths were attributed to DENV in MT during $2012^{7}$.

The aim of this study was to investigate the circulation and frequency of DENV serotypes in patients with acute febrile illness persisting for up to five days during a dengue outbreak in MT.

\section{MATERIALS AND METHODS}

Ethics statement and clinical samples: Previously, the internal review board of the Julio Müller University Hospital Ethics Committee on Research approved the proceedings involving human samples in this observational cross-sectional study, registered under the No. 100/2011.

Between October 2011 and July 2012, 604 patients with acute febrile illness persisting for up to five days, from 20 cities in MT, attended in the Public Health Central Laboratory were included in this study. All clinical and epidemiological data obtained through the SINAN records and from the patients were handled anonymously and confidentially.

Inoculation in $\mathbf{C 6 / 3 6}$ cells and indirect immunofluorescence for DENV serotypes and YFV: C6/36 cells (ATCC CRL-1660) cultured in tubes containing $1 \mathrm{~mL}$ of L-15 medium supplemented with $5 \%$ fetal bovine serum, non-essential amino acids and glutamine were inoculated with $20 \mu \mathrm{L}$ of serum. After five to seven days, indirect immunofluorescence (IFI) was performed in the inoculated cells using polyclonal antibodies against flaviviruses $(1: 100)$. Positive samples were subjected to a second assay using monoclonal antibodies for DENV-1, 2, 3 , and 4 and YFV (1:800). Anti-mouse $\operatorname{IgG}(1: 1,000)$ was used in both reactions. The IFI was performed at the Central Public Health Laboratory of Mato Grosso (LACEN-MT) according to standard protocols and reagents provided by the Brazilian Ministry of Health.
Viral RNA extraction and multiplex semi-nested RT-PCR for flaviviruses: Viral RNA extracted from $140 \mu \mathrm{L}$ of serum using the QIAamp Viral RNA mini kit (Qiagen, Hilden, Germany), according to the manufacturer's instructions, was subjected to reverse transcription. The protocol targets a region of $958 \mathrm{bp}$ from the NS5 gene of flaviviruses and was used with some modifications ${ }^{6}$. Briefly, the extracted RNA ( 9 $\mu \mathrm{L}$ ) was reverse transcribed to cDNA using $100 \mathrm{U}$ of Superscript III (Invitrogen), genus-specific reverse primer FG2 $(15 \mu \mathrm{M})$, and $20 \mathrm{U}$ of RNase inhibitor (RNaseOUT; Invitrogen).

Complementary DNA $(8 \mu \mathrm{L})$ was amplified in a semi-nested multiplex PCR reaction for 11 flaviviruses: DENV-1 (472 bp), DENV-2 (316 bp), DENV-3 (628 bp), DENV-4 (222 bp), YFV (253 bp), SLEV (232 bp), WNV (195 bp), ROCV (230 bp), Bussuquara (BSQV; 388 bp), Iguape (IGUV; $254 \mathrm{bp}$ ), and Ilheus viruses (ILHV; $474 \mathrm{bp}$ ) as previously described ${ }^{6}$. Positive specimens were tested twice in independent single or duplex RTPCR reactions, depending on whether they were single or co-infections, respectively, with the same forward and species-specific reverse primers.

Viral RNA of DENV-1 genotype I strain Mochizuki, DENV2 isolate $\mathrm{SpH}$ 125367, DENV-3 genotype III strain RPDen06/41, DENV-4 genotype II strain Boa Vista, SLEV genotype V-B strain BeH 355964, YFV 17DD, and ILHV isolate BeH 7445 were included as positive controls, as well as a no-template control. Precautions to avoid contamination were followed. Positive controls used in the study were sequenced and compared to sequences obtained from DENV-positive patients to exclude the possibility of contamination.

Nucleotide sequencing and analysis of RT-PCR amplicons: Amplicons obtained by single semi-nested RT-PCR for DENV serotypes were sequenced (3500 Genetic Analyzer, Applied Biosystems (Thermo Fisher Scientific Inc., Waltham, MA, USA). Nucleotide sequences, aligned with MEGA (5.0) and Geneious (6.0.6), were compared with DENV reference sequences (BLASTn; NCBI). All NS5 partial nucleotide sequences were deposited at the GenBank database, and they can be accessed through their corresponding accession numbers.

Data analysis: A database with the SINAN data was introduced in Epidata Entry (Version 3.1), analyzed with Epidata Analysis (2.2.2.178) and Microsoft Excel 2010. Descriptive analysis and the two-proportion test were conducted to verify the relationship of symptoms and infection with arboviruses.

\section{RESULTS}

Molecular identification and frequency of DENV serotypes in patients from MT: Among the 604 patients suspected of dengue, 331 (54.8\%) were positive for DENV by RT-PCR in 17 municipalities of MT. Molecular identification of DENV serotypes indicated that, within the subset of positive samples, 321 had single infections, including 305 with DENV-4, 15 with DENV-1, and one with DENV-3. Co-infections were detected by RT-PCR in 10 (3.0\%) of the 331 patients: nine were co-infected with DENV-1 and DENV-4 in Cuiaba (3; 30.0\%), Sinop $(3 ; 30.0 \%)$, Sorriso $(2 ; 20.0 \%)$, and Santa Carmem $(1 ; 10.0 \%)$, and one $(10.0 \%)$ was co-infected with DENV-2 and DENV-4 from Cuiaba. In Cuiaba, all four DENV serotypes were identified (eight patients were positive for DENV-1, one for DENV-2, one for DENV-3, and 244 for DENV-4) (Tables 1 and 2). 
Table 1

Social and demographic characteristics of patients infected with DENV-1 and DENV-4 in Mato Grosso between October 2011 and July 2012

\begin{tabular}{|c|c|c|c|c|c|}
\hline \multirow{2}{*}{ Characteristics } & & \multicolumn{2}{|c|}{ DENV-1 } & \multicolumn{2}{|c|}{ DENV-4 } \\
\hline & & $\mathrm{N}^{*}$ & $\%$ & $\mathrm{~N}^{*}$ & $\%$ \\
\hline \multirow{2}{*}{ Sex } & Male & 8 & 33.3 & 157 & 49.8 \\
\hline & Female & 16 & 66.7 & 158 & 50.2 \\
\hline \multirow{3}{*}{ Pregnancy } & Yes & 1 & 6.2 & 6 & 3.8 \\
\hline & No & 13 & 81.3 & 130 & 82.3 \\
\hline & NA & 2 & 12.5 & 22 & 13.9 \\
\hline \multirow{8}{*}{$\begin{array}{l}\text { Age } \\
\text { (years) }\end{array}$} & $<5$ & 0 & 0 & 10 & 3.2 \\
\hline & $5-9$ & 2 & 8.3 & 20 & 6.3 \\
\hline & $10-14$ & 3 & 12.5 & 35 & 11.1 \\
\hline & $15-19$ & 2 & 8.3 & 37 & 11.7 \\
\hline & 20-39 & 11 & 45.9 & 135 & 42.9 \\
\hline & $40-59$ & 6 & 25.0 & 66 & 21.0 \\
\hline & $>59$ & 0 & 0 & 11 & 3.5 \\
\hline & NA & 0 & 0 & 1 & 0.3 \\
\hline \multirow{6}{*}{ Ethnicity } & White & 7 & 29.2 & 57 & 18.1 \\
\hline & Brown & 11 & 45.8 & 170 & 54.0 \\
\hline & Black & 2 & 8.3 & 16 & 5.1 \\
\hline & Yellow & 0 & 0 & 4 & 1.3 \\
\hline & Others & 0 & 0 & 3 & 0.9 \\
\hline & NA & 4 & 16.7 & 65 & 20.6 \\
\hline \multirow{3}{*}{ Area } & Urban & 23 & 95.8 & 299 & 94.9 \\
\hline & Rural & 1 & 4.2 & 10 & 3.2 \\
\hline & NA & 0 & 0 & 6 & 1.9 \\
\hline \multirow{3}{*}{$\begin{array}{l}\text { Previous history } \\
\text { of similar disease }\end{array}$} & Yes & 3 & 12.5 & 54 & 17.1 \\
\hline & No & 16 & 66.7 & 179 & 56.8 \\
\hline & NA & 5 & 20.8 & 82 & 26.0 \\
\hline \multirow{3}{*}{$\begin{array}{l}\text { History of } \\
\text { rural/sylvatic } \\
\text { access }\end{array}$} & Yes & 1 & 4.2 & 23 & 7.3 \\
\hline & No & 18 & 75.0 & 208 & 66.0 \\
\hline & NA & 5 & 20.8 & 84 & 26.7 \\
\hline \multirow{10}{*}{ City of residence } & Cuiaba & 8 & 33.3 & 244 & 77.5 \\
\hline & Várzea Grande & 1 & 4.2 & 33 & 10.5 \\
\hline & Sinop & 9 & 37.5 & 7 & 2.2 \\
\hline & Pontes e Lacerda & 0 & 0 & 5 & 1.6 \\
\hline & Sorriso & 4 & 16.7 & 5 & 1.6 \\
\hline & Pocone & 0 & 0 & 5 & 1.6 \\
\hline & Nova Mutum & 0 & 0 & 2 & 0.6 \\
\hline & Santa Carmem & 2 & 8.3 & 1 & 0.3 \\
\hline & Outros & 0 & 0 & 13 & 4.1 \\
\hline & NA & 0 & 0 & 0 & 0 \\
\hline
\end{tabular}

*The difference in the number of patients included in the variables is due to the existence of co-infections by DENV-1 and DENV-4. NA= information was not available/applicable (child/elderly).
In contrast, of the 604 specimens, only 150 (24.8\%) were positive for DENV-4 and 19 (3.1\%) for DENV-1, as determined by immunofluorescence following inoculation in C6/36 cells. Only two samples positive by ICC/IFA were not positive by RT-PCR for DENV-4 and other two for DENV-1. One sample from Pontes e Lacerda, MT, was positive for DENV-1 in the ICC/IFA and negative for this serotype in the RT-PCR, but positive for DENV-4.

RNA extracted from the serum of all patients that tested positive for DENV-1, 2, and 3, or with co-infections, was tested at least twice in independent reactions and confirmed by nucleotide sequencing.

Three patients were co-infected by SLEV and DENV-4 in Varzea Grande and Cuiaba. These results will be described separately in a study involving mosquito samples as well. The remaining 273 patients $(45.2 \%)$ were negative for the 11 flaviviruses screened using the multiplex seminested RT-PCR.

Clinical and epidemiological characterization of DENV-positive patients: Among the 331 patients positive for DENV, DENV-4 was the most prevalent serotype, detected in 315 (95.2\%) patients from 17 distinct municipalities, most of them $(277 ; 87.9 \%)$ residents of the metropolitan area of Cuiaba and Varzea Grande, in south-central MT (Table 1). DENV-1 was detected in 24 (7.2\%) patients from five cities, mainly in mid-north MT and in Cuiaba (Table 1; Fig. 1). Nucleotide sequences of DENV-1 (472 bp; accession numbers KM085990, KM085991) showed 97\% similarity with 242/2010/BR/ $\mathrm{RJ} / 2010$ (KF672759) and 99\% with the sequence MT/SINOP/132/2011 (KF35670), both from genotype V, American/African lineage. DENV-4 sequences (222 bp; accession numbers KM085994, KM085995, KM085996 and KM085997) showed 99\% similarity with strains of DENV-4 genotype II circulating in Brazil.

Clinical and epidemiological aspects were evaluated according to parameters established by the Brazilian Ministry of Health. Among all the parameters included in the analysis, a statistical correlation was found only between having DENV-4 infection, being an urban resident and absence of previous similar disease. However, patients aged 20-39 were the most affected, with 142/331 (42.9\%) patients in this age group, followed by the 40-59-year-old group $(69 / 331 ; 20.8 \%)$. Co-infections were also more frequent in these two groups, with four $(44.5 \%)$ in the $20-39$ age group, three $(33.3 \%)$ in the $40-59$ age group, one $(11.1 \%)$ in the five-nine age group, and one $(11.1 \%)$ in the $10-14$ age group. Children under the age of five and the elderly presented a slightly higher prevalence, with $10 / 18(55.5 \%)$ and $11 / 21$ (52.4\%) positive cases, respectively. Men and women were affected equally by DENV-4. However, 66.7\% (16/24) of patients positive for DENV-1 were women. Co-infections by DENV-1 and DENV-4 were also more frequent in women $(66.7 \%$; 6/9) (Table 1$)$.

One patient, a twelve-year-old male resident of the city of Cuiaba, who presented hyperthermia, headache, emesis and epigastric pain, and without history of similar disease, travel or recent access to rural/ sylvatic areas, was co-infected with DENV-2 and DENV-4. The partial nucleotide sequence of the NS5 gene of DENV-2 (316 bp; accession number KM085992) showed 97\% similarity with several DENV-2 strains, including the sequence of the BR42727/RJ/91 (accession number HQ012534) genotype Asian/American lineage I. 
HEINEN, L.B.S.; ZUCHI, N.; CARDOSO, B.F.; SANTOS, M.A.M.; NOGUEIRA, M.L. \& DEZENGRINI-SLHESSARENKO, R. - Dengue outbreak in Mato Grosso State, Midwestern Brazil. Rev. Inst. Med. Trop. Sao Paulo. 57(6): 489-96, 2015.

Table 2

Clinical aspects and classification of dengue patients according to serotype or co-infection by dengue viruses in Mato Grosso, 2011-2012

\begin{tabular}{|c|c|c|c|c|c|c|c|c|c|c|}
\hline \multirow{2}{*}{ Manifestation } & \multicolumn{2}{|c|}{ DENV-1 } & \multicolumn{2}{|c|}{ DENV-3 } & \multicolumn{2}{|c|}{ DENV-4 } & \multicolumn{2}{|c|}{ DENV-1/DENV-4 } & \multicolumn{2}{|c|}{ DENV-2/DENV4 } \\
\hline & $\mathrm{N}$ & $\%$ & $\mathrm{~N}$ & $\%$ & $\mathrm{~N}$ & $\%$ & $\mathrm{~N}$ & $\%$ & $\mathrm{~N}$ & $\%$ \\
\hline Hyperthermia & 13 & 86.7 & 1 & 100.0 & 243 & 79.7 & 8 & 88.9 & 1 & 100.0 \\
\hline Myalgia & 13 & 86.7 & 1 & 100.0 & 220 & 72.1 & 8 & 88.9 & 0 & 0.0 \\
\hline Headache & 12 & 80.0 & 1 & 100.0 & 199 & 65.2 & 8 & 88.9 & 1 & 100.0 \\
\hline Ocular pain & 2 & 13.3 & 0 & 0.0 & 126 & 41.3 & 3 & 33.3 & 0 & 0.0 \\
\hline Prostration & 6 & 40.0 & 0 & 0.0 & 79 & 25.9 & 2 & 22.2 & 0 & 0.0 \\
\hline Arthralgia & 2 & 13.3 & 0 & 0.0 & 79 & 25.9 & 6 & 66.7 & 0 & 0.0 \\
\hline Emesis & 3 & 20.0 & 1 & 100.0 & 42 & 13.8 & 0 & 0.0 & 1 & 100.0 \\
\hline Nausea & 2 & 13.3 & 0 & 0.0 & 40 & 13.1 & 3 & 33.3 & 0 & 0.0 \\
\hline Anorexia & 0 & 0.0 & 0 & 0.0 & 18 & 5.9 & 1 & 11.1 & 0 & 0.0 \\
\hline Epigastric pain & 0 & 0.0 & 0 & 0.0 & 14 & 4.6 & 0 & 0.0 & 1 & 100.0 \\
\hline Pruritus & 1 & 6.7 & 0 & 0.0 & 8 & 2.6 & 0 & 0.0 & 0 & 0.0 \\
\hline Dizziness & 0 & 0.0 & 0 & 0.0 & 4 & 1.3 & 0 & 0.0 & 0 & 0.0 \\
\hline Hemorrhagic signs & 3 & 20.0 & 0 & 0.0 & 66 & 21.6 & 2 & 22.2 & 0 & 0.0 \\
\hline \multicolumn{11}{|l|}{ Classification } \\
\hline Dengue without warning signs & 12 & 80.0 & 1 & 100.0 & 248 & 81.8 & 9 & 100.0 & 0 & 0.0 \\
\hline Dengue with warning signs & 2 & 13.3 & 0 & 0.0 & 13 & 4.3 & 0 & 0.0 & 1 & 100.0 \\
\hline Severe dengue & 0 & 0.0 & 0 & 0.0 & 1 & 0.3 & 0 & 0.0 & 0 & 0.0 \\
\hline
\end{tabular}

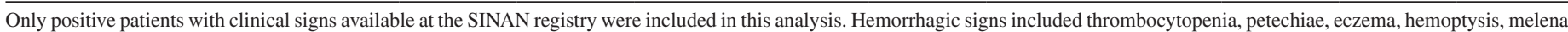
and gingivorrhagia. DENV: dengue virus serotype $1,2,3$ or 4 ; N: number; \%: percent of positive patients.

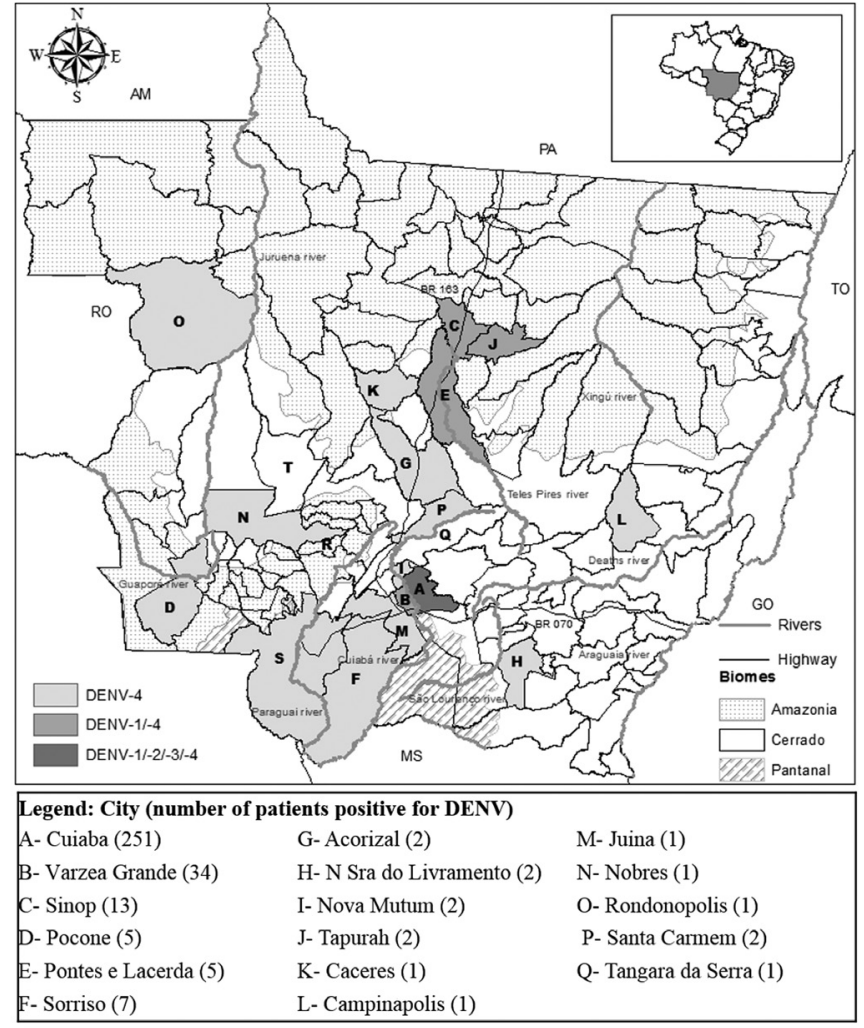

Fig. 1. - Distribution of patients with acute febrile illness positive for dengue virus (DENV) serotypes by multiplex semi-nested RT-PCR in Mato Grosso, West-central Brazil during 2011-2012.
Another patient, a ten-year-old girl living in Cuiaba, who presented hyperthermia, headache, myalgia and emesis, with a previous history of similar illness and without a history of recent travel or visit to rural/ sylvatic areas, was positive for DENV-3. The NS5 partial nucleotide sequence (628 bp; accession number KM085993) presented 96\% similarity with the sequence of the DENV-3 BR/BID-V3590/2007 isolate (accession number GU131869) belonging to genotype III of Caribbean/ South America lineage from Sao Paulo.

The most frequent symptoms in patients infected with DENV serotypes included hyperthermia $(82.8 \%)$, myalgia $(75.4 \%)$, headache (66.0\%), and hemorrhagic manifestations (21.5\%), including thrombocytopenia, petechiae, hemoptysis, eczema, and gingival bleeding. Co-infected patients presented hyperthermia $(90.0 \%)$, headache $(90.0 \%)$, myalgia $(80.0 \%)$, arthralgia $(60.0 \%)$, and retrorbital pain $(30.0 \%)$ (Table 2). Most of the sampled and, consequently, infected patients, described themselves as belonging to a mixed ethnic group (mixture of white and black) (Table 1).

Based on the clinical manifestations, the majority $(81.6 \%$; 270/331) of dengue-positive patients were classified as having dengue without warning signs and, some were classified as having dengue with warning signs $(5.1 \% ; 16 / 331)$, according to the clinical data obtained at the time of sample collection (Table 2). Among the co-infected patients, nine of the 10 co-infected with DENV-1/DENV-4 were classified as having dengue without warning signs, while only one patient co-infected with DENV-2/ DENV-4 was diagnosed with dengue with warning signs. Severe dengue was registered in only one DENV-4 patient. Statistically, no differences were observed in the clinical data obtained at the time of sample collection between patients with single infections or co-infections; there was also no difference in the clinical characteristics of patients showing positivity 
for different DENV serotypes (Table 2). However, clinical follow-up was not performed for these patients.

Most of the individuals were sampled in May, and at that time $50.5 \%$ $(157 / 311)$ of them were positive for DENV; however, a higher prevalence of the virus was seen in April (73.3\%; 44/60).

\section{DISCUSSION}

Arboviruses pose a significant public health problem worldwide. The incidence of dengue and the geographical distribution of DENV serotypes have expanded in the past decades, despite efforts through governmental programs to control vector proliferation and disease incidence. Dengue is responsible for large outbreaks worldwide, with an estimated 390 million infections every year, of which 96 million are clinically apparent, mainly in tropical and subtropical areas ${ }^{18,43}$.

Brazil contributed with a significant number of dengue cases in the Americas' reported to the $\mathrm{WHO}^{34}$. In this regard, studies aimed to identify risk factors for DENV transmission, the spatial distribution of vector populations and serotype frequency are important to comprehend the epidemiological determinants contributing to disease's spreading. Moreover, Brazil is a country with a surface area of over eight million $\mathrm{km}^{2}$, meaning that epidemiological findings may vary significantly between regions.

In Brazil, DENV serotypes are widely dispersed. The disease has been considered endemic since 1995 in MT. In recent decades, economic factors associated with the uncontrolled urbanization, dispersal and adaptation of Ae. aegypti have contributed to the cyclical occurrence of dengue epidemics ${ }^{35}$. However, studies involving the distribution and frequency of serotypes, in the MT population, are lacking. For this reason, in this study, we aimed to characterize the circulation of flaviviruses in patients with acute febrile illness during a dengue outbreak in MT.

Most of the patients included in this study presented DENV-4 RNA in their serum samples, which can be attributed to the recent introduction of this serotype in the state, and a few patients were positive for DENV-1 RNA, corroborating the data from the State Health Authority ${ }^{7}$. DENV-4 infection was more common in mid-southern MT, whereas DENV-1 predominated in the north region of the state and in Cuiaba. Moreover, two patients from Cuiaba without a history of recent travel tested positive for DENV-2 and DENV-3, indicating that these serotypes may have circulated in the state during this period.

Although underreporting is common, between January and April of $2012,81.6 \%$ of the dengue cases $(286,011$ cases) were reported in ten Brazilian states ${ }^{26}$. The southeastern region of the country had the highest positivity for DENV, representing $41.7 \%$ of cases $(49.7 \%$ of them caused by DENV-4, $46.8 \%$ by DENV-1, $3.4 \%$ by DENV-2, and $0.1 \%$ by DENV-3), followed by $36.3 \%$ in the northeastern region $(81.5 \%$ by DENV-4, $16.8 \%$ by DENV-1, $0.9 \%$ by DENV-2, and $0.8 \%$ by DENV-3). Also, $10.5 \%$ of the cases were registered in the north region of Brazil ( $59.3 \%$ by DENV-4, $36.4 \%$ by DENV-1, $4.1 \%$ by DENV-2, and $0.2 \%$ by DENV-3), $10.3 \%$ in the midwestern region ( $53.3 \%$ by DENV-1, $36.6 \%$ by DENV-4, and $10.1 \%$ by DENV-2), and $1.2 \%$ in the South $(83.8 \%$ by DENV-1, $13.5 \%$ by DENV-4, and $2.7 \%$ by DENV- 2$)^{26}$.
DENV-4 was the predominant serotype causing epidemics in the Southeast, North, and Northeast, followed by DENV-1, which was more frequent in the midwestern and southern regions. The states of Rio de Janeiro, Bahia, and Pernambuco registered higher incidences, while MT ranked seventh in terms of reported cases. Despite MT belongs to the midwestern region, the vast majority of cases observed in the state were caused by DENV-4 (96.3\%), with 8,101 cases per 100,000 inhabitants in Cuiaba, representing the fourth highest incidence among cities in Brazil in $2012^{26}$.

Only half $(150 / 315 ; 47.6 \%)$ of the positive samples for DENV-4 by RT-PCR were also positive by immunofluorescence following inoculation in C6/36 cells. DENV-2- and DENV-3-positive samples and co-infections reported here were not identified using this technique, emphasizing the importance of molecular identification and typing for arboviruses ${ }^{24}$. Most of the positive samples by ICC/IFA were also positive by RT-PCR. It is possible that freezing/thawing the samples, combined with antigenic variability and the well described increased sensitivity of molecular techniques in comparison with viral isolation, have influenced these results.

The coexistence of the four DENV serotypes in an endemic area with subsequent epidemics is described as a hyperendemic state ${ }^{30}$. This scenario was reported in 2002 in Puerto Rico and in 2008 in Delhi, India, and in several districts in Nepal ${ }^{5,23,32}$. In Brazil, the circulation of the four serotypes was reported in Manaus, Sao Paulo, and Rio de Janeiro in $2011^{4,27,41}$. The city of Cuiaba, which is the capital of MT, has demographic, climatic, and environmental conditions that favor vector proliferation and consequently the epidemiological cycle of the virus. The last survey of the Ae. aegypti rapid index (LIRAa), conducted in Cuiaba during 2012, indicated a mean larval infestation of 3.1, considered as elevated risk for DENV transmission ${ }^{7}$. Moreover, the genotypes of DENV circulating in MT in 2012, namely DENV-1 genotype V, DENV-2 Southeast Asian/American genotype, DENV-3 genotype III, and DENV4 genotype II, are the predominant genotypes within these serotypes circulating in Brazil, including Manaus, AM in 201124.

The introduction of new DENV serotypes in fully susceptible populations, associated to a high density of vector mosquitoes, propitiate the occurrence of large outbreaks ${ }^{9,15,32}$. In this regard, DENV-4 was first detected in central-south MT in 2012. This serotype had never been previously reported in the state, and it has probably replaced another circulating serotype, such as DENV-1, in the population. Most of the DENV-4-infected patients where from Cuiaba and Varzea Grande $(277 / 315 ; 87.9 \%)$. In the north of the state, DENV-1 remained more prevalent $(15 / 24 ; 62.5 \%)$.

Statistical analysis revealed an association between DENV-4 infection, residency in urban areas and absence of previous history of similar disease. These findings were expected since dengue is considered an exclusively urban disease in the Americas ${ }^{40}$. Furthermore, DENV-4 was not reported in Brazil since 1981. Immunity resulting from previous exposure to DENV is serotype specific. Cross-protection is observed only for a few months after the onset of disease. However, only serological studies involving the detection of serotype-specific $\operatorname{IgM}$ and $\mathrm{IgG}$ can elucidate the hypothesis of primary infection since most DENV infections are subclinical. The lack of statistical association between DENV-1, DENV-2 and DENV-3 infection with possible risk factors and clinical 


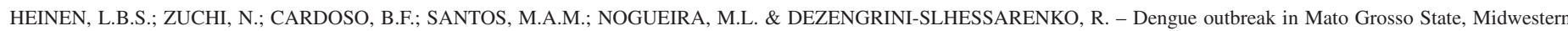
Brazil. Rev. Inst. Med. Trop. Sao Paulo. 57(6): 489-96, 2015.

data, in this study, may be due to the low number of DENV-positive patients carrying these serotypes, especially when compared to the number of patients included in the study.

The nine cases of co-infections by DENV-1 and DENV-4, and one by DENV-2 and DENV-4 were found in Cuiaba. Co-infections are more frequent in tropical areas where different serotypes co-circulate ${ }^{14,24}$. Risk factors for DENV infections and co-infections include the virulence of the circulating serotype, the immunity status of the human population, and the density of vector population, leading to multiple exposures to infected mosquitoes ${ }^{5,14}$.

The first report of co-infection by DENV serotypes occurred in Puerto Rico in 1982. Co-infections occur naturally and are not necessarily associated with increased disease severity. In Brazil, co-infections by DENV-2/DENV-3 were reported in Taua, in the state of Ceara ${ }^{2}$; by DENV-2/DENV-4, DENV-1/DENV-2, DENV-1/DENV-4, and DENV-3/ DENV-4 in Manaus AM ${ }^{4,24}$; and by DENV-1/DENV-4 in Sao Jose do Rio Preto, $\mathrm{SP}^{8}$. Because clinical follow up was not performed in this study, it is not possible to determine whether co-infections resulted in increased disease severity. Some authors have noticed that concurrent infections by different DENV serotypes may increase severity due to increased virus titers and other factors ${ }^{24}$. The absence of a clinical correlation between co-infections and disease outcome has already been reported ${ }^{8}$.

In this study, the co-infection by DENV-2/DENV-4 was classified as dengue with warning signs, while all co-infections by DENV-1/ DENV-4 were classified as dengue without warning signs. This may be due to the fact that the Southeast Asian/American DENV-2 genotype is usually more virulent than other serotypes/genotypes and has been the most prevalent genotype of DENV-2 circulating in Brazil in the past 15 years ${ }^{24}$. Most infected patients reported their ethnicity as a mixture of white and black (Table 1), and in MT, 55\% of the population belongs to this ethnic group ${ }^{20}$.

The recent introduction of DENV-4 in MT, which accounted for $95.2 \%$ of the cases in the state, may be responsible for the higher incidence in the 20-39 age group, since DENV-4 remained undetected in the country between 1981 and 2008. During this period, young adults remained seronegative and consequently fully susceptible to infection by DENV-4 ${ }^{13}$. In previous studies, a higher incidence of dengue was observed in the patients on the age groups of five-14 and 15-19 in Cuiaba, probably resultant from the endemic state of MT for other serotypes despite DENV-4 ${ }^{35}$. Since the distribution of the population from MT between several age groups is proportional, the age of the population is not a factor that affects the incidence of the disease in $\mathrm{MT}^{13}$.

Population immunity in areas where dengue outbreaks occur frequently influences the incidence of the disease among the different age groups. Co-circulation of DENV serotypes for extended periods in a given area is thought to increase exposure. Consequently, adults present higher frequencies of monotypic immunity to DENV serotypes than children. Therefore, the cumulative effect on the adults immune system due to several episodes of dengue caused by different DENV serotypes may explain the higher predominance of dengue in younger age groups in hyperendemic areas ${ }^{34}$.

In our study, hemorrhagic manifestations were not more frequent in children younger than the age of five, or in the elderly, demographic groups considered more prone to severe dengue. However, this study enrolled patients with acute manifestations (one-five days since the symptoms onset), while hemorrhagic fever generally develops later in the course of the infection. Despite the reduced number of children younger than the age of five included in the present study, when considering patients in the same age group, hemorrhagic manifestations were more frequent within this age group, similar to reports from Southeast Asia and North Brazil ${ }^{21,33}$.

Approximately $45 \%$ of the sampled patients with undifferentiated acute febrile illness where negative for flaviviruses. Other infectious diseases and biochemical/hematological results were not systematically investigated, and the requirement for low temperatures and agility to process the samples, associated with the relatively high mean ambient temperature observed in Cuiaba, may have contributed to these negative results, especially regarding ICC/IFA.

There is no available data concerning the frequency of the DENV serotypes in the MT population in previous years. The results presented in this study highlight the need for a broad entomological and virological surveillance in order to deepen our understanding of the epidemiology of dengue in MT.

\section{RESUMO}

\section{Surto de dengue em Mato Grosso, centro-oeste do Brasil}

$\mathrm{O}$ vírus da dengue (DENV) é o arbovirus mais frequente no mundo. Neste estudo, é relatada uma epidemia de grandes proporções no estado de Mato Grosso (MT). Amostras de soro de 604 pacientes com doença febril aguda a menos de 5 dias foram inoculadas em células C6/36 seguida de Imunofluorescência indireta para os sorotipos do DENV e vírus da febre amarela e submetidas a multiplex-semi-nested-RT-PCR para 11 flavivírus. O DENV-4 foi isolado em 150/604 (24,8\%) e DENV-1 em 19/604 (3,1\%) amostras. Por RT-PCR, 331 (54,8\%) pacientes foram positivos para DENV; 321 com infecções únicas (DENV-4 n=305; DENV$1 \mathrm{n}=15$; DENV-3 n=1), nove co-infecções entre DENV-1/DENV-4 e uma com DENV-2/DENV-4. O DENV-4 foi detectado em 315/331 (95,2\%) pacientes de 17 municípios e o DENV-1 em 24/331 (7,2\%) pacientes de 5 cidades da região centro-norte de MT e em Cuiabá. A incidência de infecção foi maior em pacientes de 20-39 anos (142/331; 42,9\%). As sequências de nucleotídeos de região do gene NS5 do DENV-1 apresentaram maior similaridade com o genótipo $\mathrm{V}$, do DENV-2 com Sudeste Asiático/Americano, DENV-3 com genótipo III e DENV-4 com genótipo II, considerados os mais frequentes no Brasil. Esta epidemia coincidiu com a introdução do DENV-4 no estado. Cuiabá foi considerada hiperendêmica para os quatro sorotipos do DENV, ressaltando a necessidade de vigilância para arbovírus em MT.

\section{ACKNOWLEDGMENTS}

We wish to thank Ana E. Vininski, Sumako U. Kinoshita (LACENMT, SES), Fernanda C. Pereira, Breno F. H. Gondim, Daphne A. de Paula and Valéria Dutra (UFMT) for their technical assistance and training, and Fabio A. L. dos Santos for his help on data analysis.

Sponsorship: CNPq grant 472890/2011-5, LBSH, NZ and BFC received CAPES Master scholarships 


\section{REFERENCES}

1. Allicock OM, Lemey P, Tatem AJ, Pybus OG, Bennett SN, Mueller BA, et al. Phylogeography and population dynamics of dengue viruses in the Americas. Mol Biol Evol. 2012;29:1533-43.

2. Araújo F, Nogueira R, Araújo J, Ramalho I, Roriz M, Melo M, et al. Concurrent infection with dengue virus type- 2 and DENV-3 in a patient from Ceará, Brazil. Mem Inst Oswaldo Cruz. 2006;101:925-8.

3. Barniol J, Gaczkowski R, Barbato EV, da Cunha RV, Salgado D, Martínez E, et al. Usefulness and applicability of the revised dengue case classification by disease: multi-centre study in 18 countries. BMC Infect Dis. 2011;11:106.

4. Bastos M de S, Figueiredo RMP, Ramasawmy R, Itapirema E, Gimaque JBL, Santos LO, et al. Simultaneous circulation of all four dengue serotypes in Manaus, State of Amazonas, Brazil in 2011. Rev Soc Bras Med Trop. 2012;45:393-4

5. Bharaj P, Chahar HS, Pandey A, Diddi K, Dar L, Guleria R, et al. Concurrent infections by all four dengue virus serotypes during an outbreak of dengue in 2006 in Delhi, India. Virol J. 2008;5:1-5

6. Bronzoni RVDM, Baleotti FG, Nogueira MRR, Nunes M, Figueiredo LTM Duplex reverse transcription-PCR followed by nested PCR assays for detection and identification of Brazilian alphaviruses and flaviviruses. J Clin Microbiol. 2005;43:696-702.

7. Capelassi, C. A Secretaria de Estado de Saúde divulga dados da dengue de 2013 e fechamento do ano 2012. Cuiabá: Secretaria Estadual de Saúde; 2013. Available from: www.saude.mt.gov.br/noticia/3291

8. Colombo TE, Vedovello D, Mondini A, Reis AFN, Cury AAF, Oliveira FH, et al Co-infection of dengue virus by serotypes 1 and 4 in patient from medium sized city from Brazil. Rev Inst Med Trop Sao Paulo. 2013;55:275-81.

9. De Simone TS, Nogueira RMR, Araújo ESM, Guimarães FR, Santos FB, Schatzmayr HG, et al. Dengue virus surveillance: the co-circulation of DENV-1, DENV-2 and DENV-3 in the State of Rio de Janeiro, Brazil. Trans R Soc Trop Med Hyg. 2004; $98: 553-62$

10. Drumond BP, Mondini A, Schmidt DJ, Bronzoni RVDM, Bosch I, Nogueira ML. Circulation of different lineages of dengue virus 2, genotype American/Asian in Brazil: dynamics and molecular and phylogenetic characterization. PLOS ONE. 2013;8:e59422.

11. Figueiredo LTM. The Brazilian flaviviruses. Microbes Infect. 2000;2:1643-9.

12. Figueiredo LTM. Dengue in Brazil. Rev Soc Bras Med Trop. 2012;45:285.

13. Figueiredo RMP, Naveca FG, Bastos MDS, Melo MN,Viana SDS, Mourão MP, et al. Dengue virus type 4, Manaus, Brazil. Emerg Infect Dis. 2008;14:667-9.

14. Figueiredo RMP De, Naveca FG, Oliveira CM, Bastos M de S, Mourão MPG, et al. Co-infection of dengue virus by serotypes 3 and 4 in patients from Amazonas, Brazil. Rev Inst Med Trop Sao Paulo. 2011;53:321-3.

15. Focks DA, Daniels E, Haile DG, Keesling JE. A simulation model of the epidemiology of urban dengue fever: literature analysis, model development, preliminary validation, and samples of simulation results. Am J Trop Med Hyg. 1995;53:489-506.

16. Gubler DJ, Kuno G, Markoff L. Flaviviruses. In: Knipe DM, Howley PM, editors. Fields virology. $5^{\text {th }}$ ed. Philadelphia: Lippincott Williams \& Wilkins; 2007. p. 1153 252.

17. Gubler DJ, Kuno G, Sather GE, Waterman SH. A case of natural concurrent human infection with two dengue viruses. Am J Trop Med Hyg. 1985;34:170-3.

18. Gubler DJ. The global emergence/resurgence of arboviral diseases as public health problems. Arch Med Res. 2002;33:330-42.
19. Holmes EC, Twiddy SS. The origin, emergence and evolutionary genetics of dengue virus. Infect Genet Evol. 2003;3:19-28.

20. Instituto Brasileiro de Geografia e Estatística. IBGE. Estimativas populacionais para os municípios brasileiros em 01.07.2011. Available from: http://www.ibge.gov.br/ home/estatistica/populacao/estimativa2011/

21. Kittigul L, Pitakarnjanakul P, Sujirarat D, Siripanichgon K. The differences of clinical manifestations and laboratory findings in children and adults with dengue virus infection. J Clin Virol. 2007;39:76-81.

22. Lindenbach BD, Thiel H-J, Rice CM. Flaviviridae: the viruses and their replication. In: Knipe DM, Howley PM, editors. Fields virology. $5^{\text {th }}$ ed. Philadelphia: Lippincott Williams \& Wilkins; 2007. p.1101-52.

23. Malla S, Thakur GD, Shrestha SK, Banjeree MK, Thapa LB, Gongal G, et al. Identification of all dengue serotypes in Nepal. Emerg Infect Dis. 2008;14:1669-70.

24. Martins VCA, Bastos M de S, Ramasawmy R, Figueiredo RP, Gimaque JBL, Braga WSM, et al. Clinical and virological descriptive study in the 2011 outbreak of dengue in the Amazonas, Brazil. PLOS ONE. 2014;9:e100535.

25. Meira R. "Urucubaca” flu or dengue? Dengue. Med Clin Sao Paulo. 1916:273-85.

26. Ministério da Saúde. Secretaria de Vigilância em Saúde. Balanço da dengue de janeiro a abril de 2012. Brasília: Ministério da Saúde; 2012. Available from: http://www slideshare.net/MinSaude/balano-dengue-i-jan-a-abr-2012

27. Nogueira RM, Eppinghaus AL. Dengue virus type 4 arrives in the state of Rio de Janeiro: a challenge for epidemiological surveillance and control. Mem Inst Oswaldo Cruz. 2011;106:255-6.

28. Nogueira RM, Miagostovich MP, Filippis AM, Pereira MA, Schatzmayr HG. Dengue virus type 3 in Rio de Janeiro, Brazil. Mem Inst Oswaldo Cruz. 2001;96:925-6.

29. Nogueira RMR, Miagostovich MP, Lampe E, Schatzmayr HG. Isolation of dengue virus type 2 in Rio de Janeiro. Mem Inst Oswaldo Cruz. 1990;85:253.

30. Oki M, Yamamoto T. Climate change, population immunity, and hyperendemicity in the transmission threshold of dengue. PLOS ONE. 2012;7:e48258.

31. Pedro A. O dengue em Nictheroy. Brazil Med. 1923;1:173-7.

32. Rigau-Pérez JG, Ayala-López A, García-Rivera EJ, Hudson SM, Vorndam V, Reiter $\mathrm{P}$, et al. The reappearance of dengue- 3 and a subsequent dengue- 4 and dengue- 1 epidemic in Puerto Rico in 1998. Am J Trop Med Hyg. 2002;67:355-62.

33. Rocha LA, Tauil PL. Dengue em criança: aspectos clínicos e epidemiológicos, Manaus, Estado do Amazonas, no periodo de 2006 e 2007. Rev Soc Bras Med Trop. 2009;42:18-22.

34. Rodriguez-Barraquer I, Cordeiro MT, Braga C, de Souza WV, Marques ET, Cummings DAT. From re-emergence to hyperendemicity: the natural history of the dengue epidemic in Brazil. PLoS Negl Trop Dis. 2011;5:e935.

35. Souza LS, Barata RDCB. Intra-urbandiferentials in dengue distribution, Cuiabá, 2007-2008. Rev Bras Epidemiol. 2012;15:761-70.

36. Souza RP, Rocco IM, Maeda AY, Spenassatto C, Bisordi I, Suzuki A, et al. Dengue virus type 4 phylogenetics in Brazil 2011: looking beyond the veil. PLoS Negl Trop Dis. 2011;5:e1439.

37. Teixeira MG, Costa M da C, Barreto F, Barreto ML. Dengue: twenty-five years since reemergence in Brazil. Cad Saude Publica. 2009;25(Suppl 1):S7-18.

38. Travassos Da Rosa APA, Rocha JM, Silva OV, Lins ZC. Surto de dengue em Boa Vista, território de Roraima, Brasil. Bol Epidemiol (Rio Janeiro). 1982;14:93-100. 
HEINEN, L.B.S.; ZUCHI, N.; CARDOSO, B.F.; SANTOS, M.A.M.; NOGUEIRA, M.L. \& DEZENGRINI-SLHESSARENKO, R. - Dengue outbreak in Mato Grosso State, Midwestern Brazil. Rev. Inst. Med. Trop. Sao Paulo. 57(6): 489-96, 2015.

39. Vasconcelos PFC, Travassos da Rosa APA, Pinheiro FP, Shope RE. Arboviruses pathogenic for man in Brazil. In: Travassos da Rosa APA, Vasconcelos PFC, Travassos da Rosa JFS, editors. An overview of arbovirology in Brazil and neighbouring countries. Belém: Instituto Evandro Chagas; 1998. p. 72-99.

40. Vasilakis N, Cardosa J, Hanley KA, Holmes EC, Weaver SC. Fever from the forest: prospects for the continued emergence of sylvatic dengue virus and its impact on public health. Nat Rev Microbiol. 2011;9:532-41.

41. Villabona-Arenas CJ, de Oliveira JL, Capra C de S, Balarini K, Loureiro M, Fonseca CRTP, et al. Detection of four dengue serotypes suggests rise in hyperendemicity in urban centers of Brazil. PLoS Negl Trop Dis. 2014;8:e2620.
42. Wan S-W, Lin C-F, Yeh T-M, Liu C-C, Liu H-S, Wang S, et al. Autoimmunity in dengue pathogenesis. J Formos Med Assoc. 2013;112:3-11

43. WHO.World Health Organization. Dengue and severe dengue. Geneva: WHO; 2014. Available from: http://www.who.int/mediacentre/factsheets/fs117/en/

44. Williams M, Mayer SV, Johnson WL, Chen R, Volkova E, Vilcarromero S, et al Lineage II of Southeast Asian/American DENV-2 is associated with a severe dengue outbreak in the Peruvian Amazon. Am J Trop Med Hyg. 2014;91:601-20.

Received: 01 December 2014

Accepted: 05 March 2015 